\title{
Impacts on nontarget avian species from aerial meat baiting for feral pigs
}

\author{
By Matthew Gentle, James Speed and Anthony Pople
}

\begin{abstract}
Matthew Gentle is a Senior Zoologist and James Speed is an Experimentalist with the Robert Wicks Pest Animal Research Centre, Biosecurity Queensland (203 Tor Street, Toowoomba, Qld 4350, Australia; Email: matthew.gentle@ daff.qld.gov.au and Email: james.speed@daff. qld.gov.au). Anthony Pople is a Principal Scientist with Invasive Plants and Animals, Biosecurity Queensland (GPO Box 267, Brisbane, Qld 4001, Australia; Email: tony.pople@daff.qld. gov.au). The project arose from studies to belp improve the effectiveness and safety of feral pig management programmes.
\end{abstract}

\begin{abstract}
Summary Bait containing sodium fluoroacetate (1080) is widely used for the routine control of feral pigs in Australia. In Queensland, meat baits are popular in western and northern pastoral areas where they are readily accepted by feral pigs and can be distributed aerially. Field studies have indicated some levels of interference and consumption of baits by nontarget species and, based on toxicity data and the 1080 content of baits, many nontarget species (particularly birds and varanids) are potentially at risk through primary poisoning. While occasional deaths of species have been recorded, it remains unclear whether the level of mortality is sufficient to threaten the viability or ecological function of species. A series of field trials at Culgoa National Park in south-western Queensland was conducted to determine the effect of broadscale aerial baiting (1.7 baits per $\mathrm{km}^{2}$ ) on the density of nontarget avian species that may consume baits. Counts of susceptible bird species were conducted prior to and following aerial baiting, and on three nearby unbaited properties, in May and November 2011, and May 2012. A sample of baits was monitored with remote cameras in the November 2011 and May 2012 trials. Over the three baiting campaigns, there was no evidence of a population-level decline among the seven avian nontarget species that were monitored. Thirty per cent and $15 \%$ of baits monitored by remote cameras in the November 2011 and May 2012 trials were sampled by birds, varanids or other reptiles. These results support the continued use of 1080 meat baits for feral pig management in western Queensland and similar environs.
\end{abstract}

Key words: feral pig, invasive species, natural resource management, poison.

\section{Introduction}

E eral pigs damage the environment and are responsible for economic losses in agricultural enterprises across much of Australia (see Bengsen et al. 2014), which ultimately triggers control by land managers. Control techniques utilised include trapping, aerial and ground shooting, commercial harvesting and recreational hunting (Mitchell 2008; Gentle \& Pople 2013), but baiting with sodium fluoroacetate (1080) typically remains the most widely used and efficient technique to manage pig populations (Mitchell 2011; Bengsen et al. 2014). In Queensland, broadscale management of feral pigs, particularly in northern and western pastoral areas, remains heavily reliant upon aerial shooting or distribution of 1080 meat baits. Meat baits comprise $\sim 75 \%$ of the bait material distributed per year for feral pig control in Queensland, with large amounts (>50 tonnes) of meat baits applied annually (see Fig. 1). Meat baits are assumed to represent naturally occurring food items (e.g. carcasses) and therefore be readily

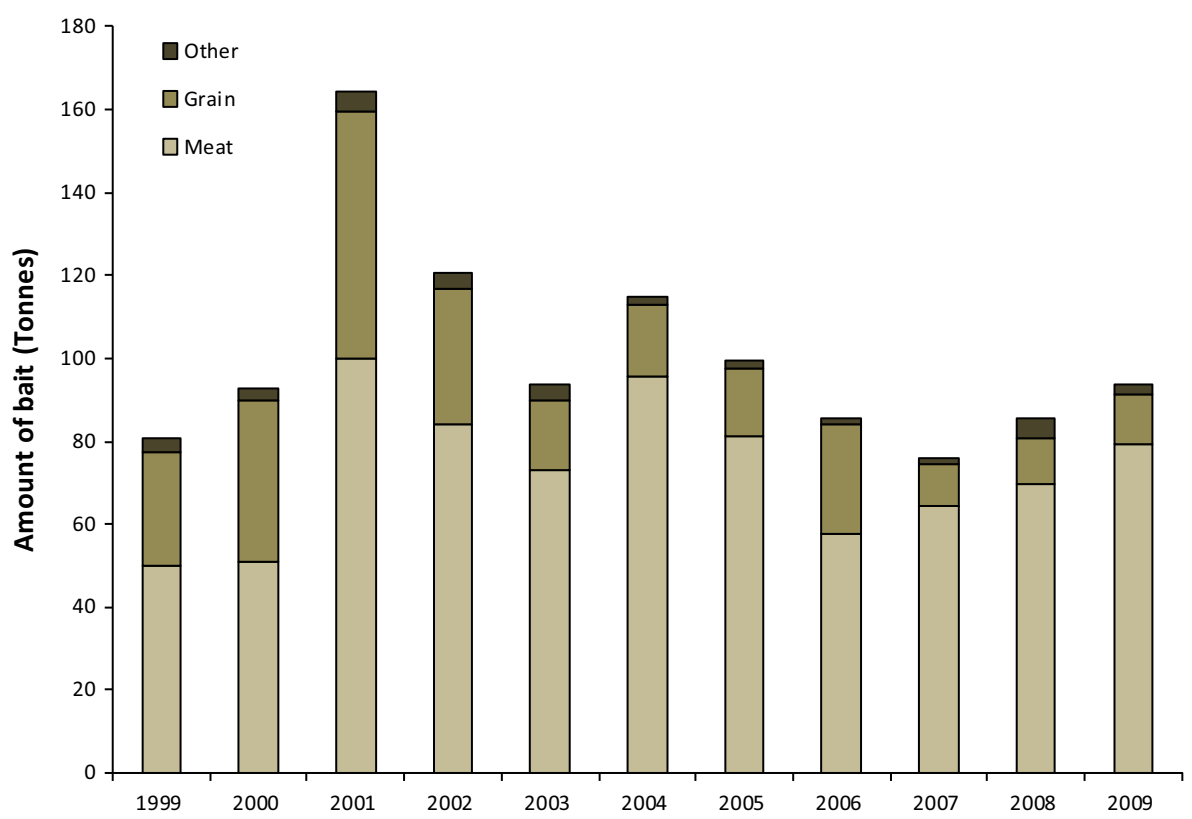

Figure 1. The amount of meat, grain and other (including fruit, vegetable and PIGOUT ${ }^{\circledR}$ ) bait mixed with 1080 to control feral pigs in Queensland, 1999-2009. Source: Queensland Department of Agriculture, Fisheries and Forestry.

accepted by pigs. Feral pigs have a relatively high tolerance of $1080\left(\mathrm{LD}_{50}\right.$ in meat bait $\sim 2.45 \mathrm{mg} / \mathrm{kg}$ body weight Gentle et al. 2008) and a large adult body size (25-175 kg; Van Dyck \& Strahan 2008), so large doses of 1080 are required to 
ensure it is lethal. Meat baits used to control feral pigs consist of $\sim 500 \mathrm{~g}$ of boneless red meat containing $72 \mathrm{mg}$ of 1080 . While such baits may be effective for reducing pig populations (Mitchell 1998), the high 1080 content poses a potential poisoning risk to nontarget consumers.

Based on published species' sensitivity to 1080 and the 1080 content in feral pig meat baits, at least 20 native Australian bird species are at risk through primary poisoning (McIlroy 1984). Birds that are likely to consume pig meat baits and would be susceptible to their 1080 content include the Australian Raven (Corvus coronoides), Australian Magpie (Cracticus tibicen), Pied Currawong (Strepera graculina), Black Kite (Milvus migrans) and Wedge-tailed Eagle (Aquila audux) (McIlroy 1983). Some species of varanid, particularly the Gould's Goanna (Varanus gouldii) are also at risk. Table 1 shows 1080 toxicity for some potential bait consumers.

A review of 1080 use in Australia highlighted the nontarget risk from pig meat baits (APVMA 2008). The surface distribution of baits, often by aircraft over extensive areas, makes it likely that many carnivorous species (particularly raptors) will encounter baits. These theoretical concerns are supported by field observations of uptake of meat baits by nontarget species (Hone \& Pedersen 1980; McIlroy 1983; Fleming et al. 2000) and, in some cases, toxicology analyses have confirmed 1080 poisoning as the cause of death $(R$. Parker, Biosecurity Queensland, 2013

Table 1. Toxicity of 1080 for a sample of potential bait consumers. Data from Mcllroy (1983)

\begin{tabular}{llll}
\hline Species & $\begin{array}{c}\text { Adult body } \\
\text { mass (g) }\end{array}$ & $\begin{array}{c}\text { LD }_{\mathbf{5 0}} \text { (mg kg }^{-1} \\
\text { body weight) }\end{array}$ & $\begin{array}{c}\text { Amount of } 1080 \\
\text { (mg) for LD }\end{array}$ \\
\hline Feral Pig (Sus scrofa) & 55000 & 1.04 & 57.20 \\
Wedge-tailed Eagle (Aquila audux) & 3100 & 9.5 & 29.45 \\
Little Raven (Corvus mellori) & 560 & 3.1 & 1.74 \\
Australian Raven & 585 & $\sim 5.1$ & $\sim 2.98$ \\
$\quad$ (Corvus coronoides) & & & \\
Australian Magpie (Cracticus tibicen) & 320 & 9.91 & 3.17 \\
Little Crow (Corvus bennetti) & 400 & 13.4 & 5.36 \\
Black Kite (Milvus migrans) & 560 & 18.5 & 10.36 \\
Laughing Kookaburra & 300 & $>6.0$ & $>1.80$ \\
$\quad$ (Dacelo novaguineae) & & & \\
Gould's Goanna (Varanus gouldii) & 840 & 43.6 & 36.62 \\
$\begin{array}{l}\text { Australian Magpielark } \\
\quad \text { Grallina cyanoleuca) }\end{array}$ & 90 & $\sim 6.75$ & 0.61 \\
\hline
\end{tabular}

Data not available for some species of interest. (primarily raptors) have been found following baiting operations (e.g. Hone \& Pedersen 1980; McIlroy 1983), but typically, few deaths have been recorded. Differences in methodology, such as bait size ( 140 g, Fleming et al. 2000; 190 g, Hone \& Pedersen 1980; 500 g, current study), the use of nontoxic bait and distribution strategies (e.g. ground $v s$ aerial, bait density), may all affect whether nontarget species find and consume bait, making comparison and interpretation of such findings difficult. Nevertheless, such information identifies species at risk.

In a review of nontarget impacts of predator baiting, Glen et al. (2007) described the evidence of impact on nontarget species as ranging from weak (such as sensitivity of a species to the toxin) to strong (such as data indicating that nontarget species can consume meat baits, or observation of some nontarget species deaths). Other factors, such as the relative palatability of the bait to each species, different species' foraging habits, availability of alternative foods, amount of bait (and toxin) consumed by each individual and the proportion of individuals in a population consuming toxic bait, can affect the extent of mortality in a population (McIlroy 1984). Given the difficulty in considering all these factors, one can only reach a definitive conclusion of negative impacts if observed mortality of nontarget species is supported by sustained reductions in population density (Glen et al. 2007). pers. comm.) Occasionally, bird carcasses
The potential for nontarget deaths, and the need for field trials to determine the impact of pig-poisoning campaigns on nontarget species, has long been recognised (see McIlroy 1983), but remains unaddressed - despite considerable study of other predator baiting practices (see Glen et al. 2007 for review). No trial has monitored 'population-level' impacts on nontarget species from meat baits used for feral pig control. This needs to be examined to ensure that feral pig baiting operations are acceptably target specific, including avoiding any broader ecological consequences (i.e. 'knock-on effects') from nontarget mortality. This study investigates the impact of pig baiting on the density of likely bait-consuming species of avifauna, particularly corvids and raptors, and briefly discusses the management implications for meat baiting practices used for feral pig control.

\section{Methods}

The most practical means to determine a population-level impact is to monitor populations of theoretically susceptible bird species for evidence of decline prior to and following baiting campaigns. Bird abundance was monitored before and after 1080 baiting campaigns on treatment (baited) and control (unbaited) sites in southwestern Queensland in autumn and spring 2011 and again in autumn 2012.

\section{Study sites}

Study sites were located in the semi-arid rangelands of south-western Queensland. Sites consisted of Culgoa Floodplain National Park (28 $\left.55^{\prime} 20^{\prime \prime} \mathrm{S}, 146^{\circ} 59^{\prime} 17^{\prime \prime} \mathrm{E}\right)$ and three nearby properties (Kulki $28^{\circ} 42^{\prime} 38^{\prime \prime} \mathrm{S}, \quad 147^{\circ} 15^{\prime} 50^{\prime \prime} \mathrm{E} ; \quad$ North Kulki $28^{\circ} 37^{\prime} 54^{\prime \prime} \mathrm{S}, 147^{\circ} 14^{\prime} 03^{\prime \prime} \mathrm{E}$; and Tambingey $28^{\circ} 38^{\prime} 17^{\prime \prime} \mathrm{S}, 147^{\circ} 08^{\prime} 10^{\prime \prime} \mathrm{E}$ ), south of Bollon, south-western Queensland (Fig. 2). Culgoa Floodplain National Park was aerially baited for feral pigs as part of a biodiversity conservation programme and served as the treatment site; Kulki, North Kulki and Tambingey served as control (i.e. nontreatment) sites. Culgoa Floodplain National Park (hereafter Culgoa; $619 \mathrm{~km}^{2}$ ) consists of relatively diverse landscapes comprising a floodplain of the 


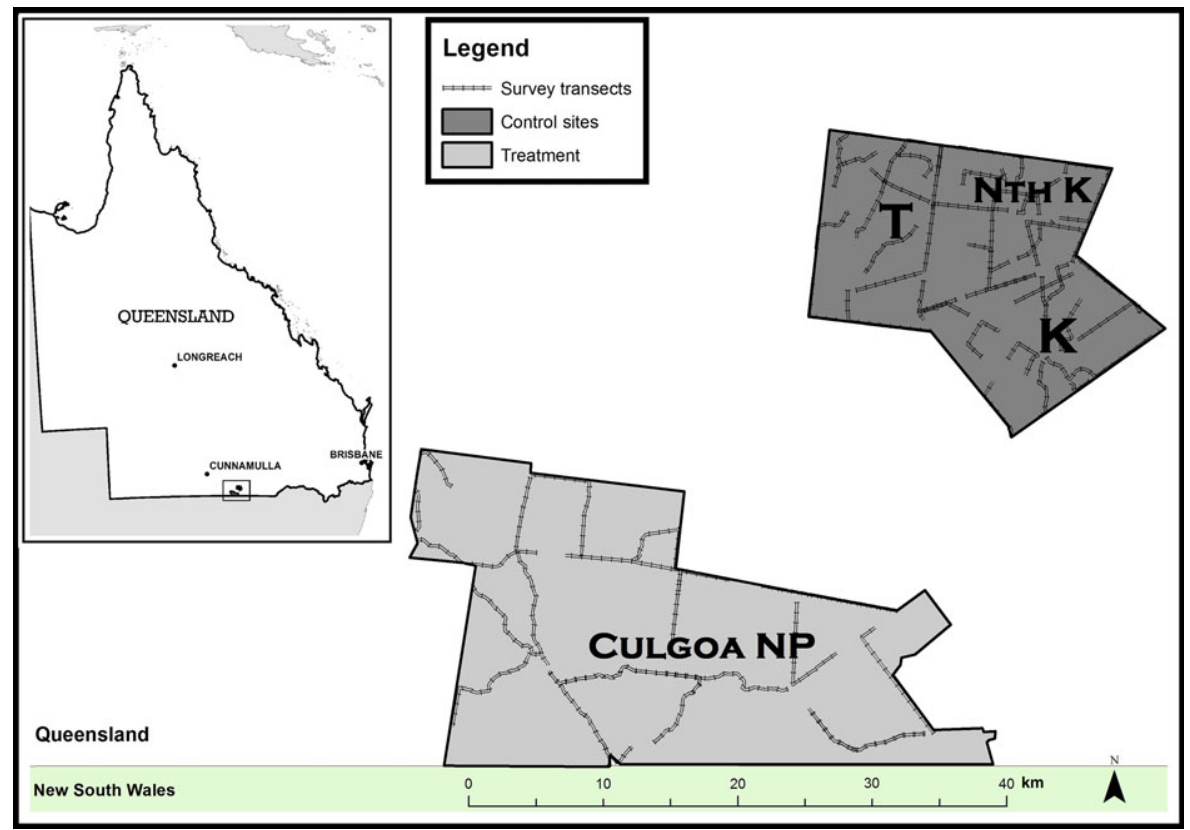

Figure 2. Location of study area in Queensland (inset) and study sites used to monitor bird populations in study area (main). Site treated with 1080 meat baits: Culgoa Floodplain National Park (Culgoa NP). Nontreatment sites: Kulki (K), North Kulki (Nth K) and Tambingey (T). The location of transects used to survey bird populations is also shown.

Culgoa River (with associated Coolabahdominated flats) with Brigalow and Gidgee, and Mulga and associated communities on the elevated stony ridge country (botanical nomenclature follows Milson 1997). Kulki $\left(122 \mathrm{~km}^{2}\right)$, North Kulki $\left(115 \mathrm{~km}^{2}\right)$ and Tambingey $\left(116 \mathrm{~km}^{2}\right)$ are nearby ( $\sim 30 \mathrm{~km}$; Fig. 2$)$ independently managed properties predominantly used for cattle and goat production, with small areas under cultivation on Kulki.

\section{Baiting}

At Culgoa (the treatment site), feral pig baiting is conducted biannually in autumn and spring (usually April/May and October/November, respectively). Baits were prepared according to the standard for feral pig control in Queensland (DEEDI 2009). Fresh pieces of kangaroo meat with a mean weight of $538 \mathrm{~g}(\mathrm{SD}=93.5$, $n=40$ ) were injected with $2 \mathrm{~mL}$ of $36 \mathrm{mg} / \mathrm{mL} 1080$ solution. Baits were distributed by aircraft on parallel, eastwest transects systematically placed at $2 \mathrm{~km}$ intervals across the study sites. Baits were spaced at $\sim 175-200 \mathrm{~m}$, to provide a bait density of $\sim 1.7$ baits per $\mathrm{km}^{2}$ within the study site boundaries.
To account for any effect of the meat bait alone on changes in bird abundance, nontoxic kangaroo meat was also distributed on the three control sites using identical methods to the Culgoa site to create a procedural control. Nontoxic and toxic baits were distributed on the control and treatment sites, respectively, before midday of the same day.

\section{Bait monitoring}

To identify the species consuming bait and potentially at risk through primary poisoning, a sample of forty 1080 baits (representing $-3.7 \%$ of total baits deployed) was monitored with cameras at Culgoa during the November 2011 and May 2012 trials. Baits were placed on the ground by hand, on the same day as the aerial bait deployment, in four transect lines of ten baits each. The transect lines were placed in habitats representative of those found within the National Park. Baits were spaced at $\sim 200$-m intervals (to simulate aerial bait spacing), at least $30 \mathrm{~m}$ from vehicle tracks. Remote digital cameras (Bolyguard $^{\circledR} /$ Scoutguard ${ }^{\circledR}$ SG550) were fixed on nearby fence posts, logs, or trees and orientated to monitor any species interact- ing with baits. All baits incorporated VHF radio transmitters $(\sim 5 \mathrm{~g}, 150 \mathrm{MHz}$, Sirtrack, Havelock North, New Zealand) to help locate, and determine the fate (i.e. consumed, not consumed) of any baits removed. Baits and monitoring cameras were checked on multiple occasions over either a 34-day (May 2012) or a 72-day (November 2011) period. The interaction of photographed individuals with each bait was classified as: (i) approached (i.e. approached bait); (ii) investigated (i.e. bait moved); (iii) sampled (i.e. chewed, pecked, torn apart or partially consumed); or (iv) consumed. Categories were not mutually exclusive; higher-level interactions also included the lower-level interactions (e.g. consumed baits were also recorded as approached, investigated and sampled). Consumed baits were not replaced. See Millar (2012) for more details on bait monitoring.

\section{Population monitoring}

Densities of selected bird species were monitored using vehicle-based surveys along predefined transects using a selection of roads, tracks and linear features (e.g. fencelines, disused bore drains) representative of the habitats in each study site. Vehicle-based surveys are well suited for surveying bird taxa that are visually conspicuous (Bibby et al. 1992; DEWHA 2010; also see Twigg \& Kay 1994), such as the species of interest in this study. In addition, the open habitats on the study sites and the need to survey large areas efficiently dictated the use of driven transects. Transects were seven to ten kilometres in length at Culgoa (19 transects), while those at Kulki, North Kulki and Tambingey (23, 22 and 13 transects, respectively) were typically $5 \mathrm{~km}$ in length. Transect length was reduced for each of the smaller control sites to maintain sufficient replication at the transect level. Each transect was driven at 10$20 \mathrm{~km}$ per hour. Where necessary, the vehicle was stopped to use binoculars to aid identification. Unidentified observations $(<1 \%$ of those recorded) were excluded from analyses. A digital rangefinder was used to estimate the perpendicular distance from the transect to each bird or group of birds detected. 
Birds were counted on sites before and after each of the three aerial baiting campaigns in May and November 2011, and May 2012. Counts were undertaken within a 10-day period immediately prior to baiting and were initiated 2-3 weeks postbaiting. Bird species monitored were those either identified as potentially carrion- or bait-consuming or known to investigate meat baits and be susceptible to 1080 (Hone \& Pedersen 1980; McIlroy 1983; M. Gentle unpublished data). These species included the Australian Magpie, Brown Falcon (Falco berigora), Australian Kestrel (Falco cenchroides), Wedge-tailed Eagle, Pied Butcherbird (Cracticus nigrogularis), Grey Butcherbird (Cracticus torquatus), Australian Raven (Corvus coronoides), Little Raven (Corvus mellori) and Torresian Crow (Corvus orru). The latter three corvid species were grouped for analyses due to difficulty in accurately distinguishing them in the field.

\section{Density estimation}

To calculate densities of each species, conventional line transect (CLT) analyses were performed in DISTANCE 6.0 (Thomas et al. 2010). Line transect methods were chosen as they are more precise and efficient for estimating density of the bird species of interest than point, cue and snapshot counts, and are particularly suited to sampling open habitats (Buckland 2006). Five detection functions were considered: a uniform key function with either a cosine or simple polynomial series expansion, a half-normal key function plus a Hermite polynomial series expansion, or a hazard-rate key function plus a cosine series expansion. Akaike's information criterion (AIC) was used to select the most parsimonious model and number of adjustment terms in the series expansion. A detection function was modelled on data pooled for each site, as sample sizes were generally inadequate $(<50)$ for each sampling period. Detection functions were expected to vary between sites more than survey periods because of differences in vegetation structure. Density estimates were then derived for each survey period using the site-specific detection function. Variance formulae are given by Buckland et al. (1993).

\section{Effect of baiting on bird abundance}

For each bird species, density estimates prior to baiting were compared to those following baiting in both the treatment and control sites. The change in density for the treatment site (Culgoa) was then compared to the change in the pooled estimate from the control sites to quantify

A split-split plot ANOVA was used to test for significant differences in mean bird abundance (birds per $\mathrm{km}^{2}$ ) between treatments (baited and unbaited), time periods (pre- and post baiting) and baiting campaigns (May 2011, September 2011 and May 2012). The main plot stratum corresponded to the site, subplot the date and sub-sub-plot pre- and post baiting. any baiting effect.
The residuals were checked for any outliers and violations of the assumption of homogeneity of residual variances. No transformations of the data were necessary. Statistical testing was performed in GenStat (16th Edition), and the level of significance set at $5 \%$ for all testing.

\section{Results}

\section{Bait monitoring}

Species groups recorded interacting with baits during both trial periods are shown in Table 2. Remote camera images recorded that many baits were visited by multiple species, on multiple occasions. Feral pigs were the primary consumer in both trial periods, consuming $15 \%$ of monitored baits. Bird species recorded
Table 2. Number of visited baits grouped by interaction category and taxa in the November 2011 (79 days) and May 2012 (34 days) trial periods. Percentages of the total baits laid are shown in parentheses

\begin{tabular}{|c|c|c|c|c|c|}
\hline Trial & Taxon & Approached & Moved & Sampled & Consumed \\
\hline \multirow{10}{*}{$\begin{array}{l}\text { November } 2011 \\
\text { (79 days) }\end{array}$} & Pig & $18(45)$ & $10(25)$ & $9(22.5)$ & $7(17.5)$ \\
\hline & Cat & $12(30)$ & $1(2.5)$ & - & - \\
\hline & Fox & $2(5)$ & $2(5)$ & $1(2.5)$ & $1(2.5)$ \\
\hline & Bird & $19(47.5)$ & $9(22.5)$ & $8(20)$ & - \\
\hline & Varanid & $24(60)$ & $13(32.5)$ & $3(7.5)$ & - \\
\hline & Other reptile & $19(47.5)$ & 7 (17.5) & $1(2.5)$ & - \\
\hline & Small mammal & $1(2.5)$ & - & - & - \\
\hline & Echidna & - & - & - & - \\
\hline & Unknown & $16(40)$ & $4(10)$ & $3(7.5)$ & $2(5)$ \\
\hline & Total & $40(100)$ & $26(65)$ & 19 (47.5) & $10(25)$ \\
\hline \multirow[t]{10}{*}{ May 2012 (34 days) } & Pig & $11(27.5)$ & $7(17.5)$ & $6(15)$ & $5(12.5)$ \\
\hline & Cat & $12(30)$ & $1(2.5)$ & $1(2.5)$ & $1(2.5)$ \\
\hline & Fox & $7(17.5)$ & $3(7.5)$ & - & - \\
\hline & Bird & $21(52.5)$ & $6(15)$ & $6(15)$ & $1(2.5)$ \\
\hline & Varanid & - & - & - & - \\
\hline & Other reptile & - & - & - & - \\
\hline & Small mammal & - & - & - & - \\
\hline & Echidna & $2(5)$ & - & - & - \\
\hline & Unknown & $1(2.5)$ & $1(2.5)$ & $1(2.5)$ & $1(2.5)$ \\
\hline & Total & $35(87.5)$ & $15(37.5)$ & $13(32.5)$ & $8(20)$ \\
\hline \multirow[t]{10}{*}{ Both trials combined } & Pig & $29(36.3)$ & $17(21.3)$ & $15(18.8)$ & $12(15)$ \\
\hline & Cat & $24(30)$ & $2(2.5)$ & $1(1.3)$ & $1(1.3)$ \\
\hline & Fox & $9(11.3)$ & $5(6.3)$ & $1(1.3)$ & - \\
\hline & Bird & $40(50)$ & $15(18.8)$ & $14(17.5)$ & $1(1.3)$ \\
\hline & Varanid & $24(30)$ & $13(16.3)$ & $3(3.8)$ & - \\
\hline & Other reptile & $19(23.8)$ & $7(8.8)$ & $1(1.3)$ & - \\
\hline & Small mammal & $1(1.3)$ & - & - & - \\
\hline & Echidna & $2(2.5)$ & - & - & - \\
\hline & Unknown & $17(21.3)$ & $5(6.3)$ & $4(5)$ & $3(3.8)$ \\
\hline & Total & 75 (93.8) & $41(51.3)$ & $32(40)$ & $18(22.5)$ \\
\hline
\end{tabular}

Categories are not mutually exclusive, for example consumed baits are also recorded in approached, investigated and sampled. 
approaching baits were the Brown Falcon, Australian Magpie, Australian Magpie Lark, Whistling Kite (Haliastur sphenurus), Pied Butcherbird, corvids and the Whitewinged Chough (Corcorax melanorhamphos). In the November 2011 trial, eight baits $(22.5 \%)$ were sampled by birds, specifically corvids (seven) and the Australian Magpie (one). Of the baits sampled by corvids, one was $\sim 20 \%$ consumed, with the seven other baits $<20 \%$ consumed. No baits were entirely consumed by birds. Varanids approached 24 baits (60\%) but only sampled three baits (7.5\%). One bait was $-30 \%$ consumed, and the remaining two $\leq 10 \%$ consumed. One of the baits partially consumed $(\sim 30 \%)$ by a Gould's Goanna was also sampled by a Shingleback Lizard (Tiliqua rugosa aspera), which consumed the remainder of the bait ( $70 \%)$. Two baits were consumed by unknown species that could not be identified due to camera failure.

In the May 2012 trial, a total of six baits (15\%) were sampled by birds including corvids (three baits), White-winged Choughs (two baits), Brown Falcon (one bait) and Whistling Kite (one bait), but the proportion of bait consumed was not assessed. One bait was consumed by a bird (Whistling Kite), and one by an unknown species. No varanids or other reptiles interacted with monitored baits during this trial period.

Pooling data from both trials, 22.5\% of baits were sampled by nontarget species, but typically, only a small proportion $(<10 \%)$ of the bait material was sampled (where this was assessed). The only nontarget species consuming entire baits were one bird (Whistling Kite) and three unknown species. This represents a $1.3 \%$ consumption rate by nontarget species, with $<4 \%$ unknown.

\section{Density estimation}

Densities of each bird taxon for each trial period are shown in Figure 3. Over all treatment and control sites, the Australian Magpie (2.2-10.8 birds per $\mathrm{km}^{2}$ ) and corvids (0.6-8.2 birds per $\mathrm{km}^{2}$ ) were the most abundant bird taxa monitored; densities of each raptor taxon were generally much lower $\left(<2.7\right.$ bird per $\left.\mathrm{km}^{2}\right)$. Collectively, there was a fluctuating, but considerable density of potentially bait-consuming birds in both control (5.8-26.6 bird per $\left.\mathrm{km}^{2}\right)$ and treatment sites $\left(6.2-12.2\right.$ bird per $\mathrm{km}^{2}$ ) over the course of the study.

\section{Effect of baiting on bird abundance}

The mean change in bird density on control and treatment sites for each baiting period for each taxon monitored is shown in Table 3. A treatment effect is shown as the difference in density changes between treatment and control sites. Comparison of the mean difference of the three trials for each taxon indicates that most species (i.e. five from the seven species/groups monitored) showed a mean increase in density following treatment. There was an overall decline in mean densities of only the Australian magpie and grey butcherbird, consistent with a negative effect of baiting.

ANOVA indicated no significant differences in bird abundance between the treatment and control sites or within sites prior to and following baiting (Table 4). However, the interaction between baiting periods and treatment (treatment versus control sites) approached significance $(P=0.055)$ for corvids indicating an inconsistent response to baiting. The baited area had higher corvid abundance in May 2011, but lower abundance in November 2011 and May 2012 compared to the average of the control sites.

The density of Australian Magpies and Pied Butcherbirds trended to decline between subsequent trial periods across all sites, but again this was not significant $(P=0.10$ and $P=0.07$, respectively).

\section{Discussion}

We found no evidence that feral pig control with aerially deployed meat baits resulted in any significant changes in the short-term abundance of potential baitconsuming birds at Culgoa National Park. Monitoring individual baits confirmed that many meat baits were approached by nontarget species, particularly corvids, Australian Magpies, raptors and varanids, but few were consumed (only $1.3 \%$ of the monitored baits laid were entirely consumed by nontarget species). How- ever, baits were often sampled (partially consumed) by birds (17.5\%), varanids and other reptiles $(\sim 5 \%)$ and unknown species (5\%). It was difficult to estimate the amount of bait consumed with confidence because baits will also decline in size and weight from rapid air-drying, and losses from insect consumption and physical breakdown. Nevertheless, the visual estimates of the amount consumed from the November 2011 trial suggest that the proportion consumed is typically low $(<10 \%)$. Consumption of even $10 \%$ of bait (at a nominal $7.2 \mathrm{mg} \mathrm{1080)} \mathrm{may} \mathrm{well}$ exceed an approximate lethal dose $\left(\mathrm{LD}_{50}\right)$ for a corvid or Australian Magpie (see Table 1). Extrapolation from $\mathrm{LD}_{50}$ may underestimate the risk to nontarget species as some susceptible individuals may be killed by consuming smaller doses, but is useful to highlight species at risk for study. Variations in toxicity and exposure to individual baits with uneven 1080 content demonstrate the difficulty in predicting susceptibility to primary poisoning through bait consumption alone. This supports the need to use more appropriate measures (viz. monitoring population-level change) to determine impacts on nontarget populations (Glen et al. 2007).

The relatively low rates of bait disturbance by birds $(\sim 19 \%)$ in our study is similar to that reported by Cowled et al. (2006) ( 7.5\%), but in strong contrast to that reported by Fleming et al. (2000), where $58 \%$ of meat baits laid were taken by birds. Methodological differences between studies are likely responsible; bait in our study (500 g, $72 \mathrm{mg} 1080$ ) was larger than that used by Fleming et al. (2000) ( 150 g, nontoxic biomarker) and Cowled et al. (2006) (250 g unpoisoned meat). Small baits would be more likely to be successfully handled and removed by nontarget species whose body weight is often $<1000 \mathrm{~g}$ (see Table 1). Bait size is known to be an important factor in nontarget poisonings in possum control operations, with small bait fragments more easily consumed by birds (Eason et al. 2011). There are often differences in the uptake and palatability of toxic and nontoxic bait, possibly because of detectability of the toxin (Sinclair \& Bird 1984; Gentle 

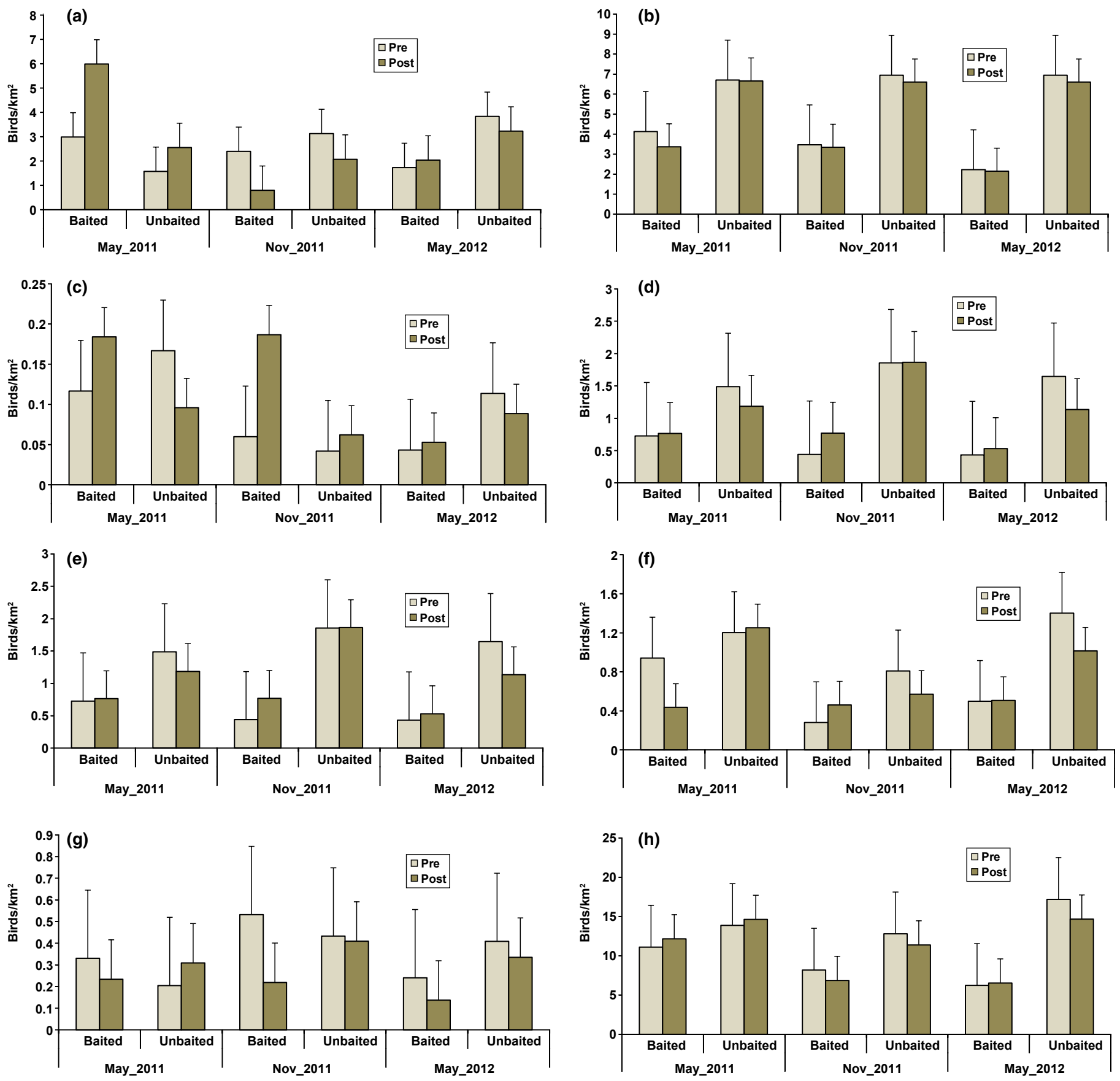

Figure 3. (a-g) Mean densities (+ estimated standard errors) of each bird taxon monitored prior to and following three baiting periods at Culgoa (baited) and Kulki, Tambingey and North Kulki (unbaited) sites. (a) Corvids, (b) Australian Magpie, (c) Wedge-tailed Eagle, (d) Falconidae, (e) Australian Kestrel, (f) Pied Butcherbird, (g) Grey Butcherbird and (h) all bird taxa.

2005). While bait composition and size may have contributed to differences in uptake, it also is likely that site or seasonal differences are contributing factors.

Regardless of the recorded interference of baits by nontargets, the results indicate no consistent, significant declines in bird abundance on the baited site (Culgoa) rel- ative to the unbaited control sites. Several species increased in abundance following baiting, but this response was inconsistent and unrelated to a treatment (baiting) effect, given similar trends on the unbaited control sites. Such fluctuations probably reflect avian species movement in response to local resource availability, which occur regularly but are difficult to predict (Chan 2001). The lack of a negative treatment effect is consistent with the birds monitored here being common and widespread in the semi-arid areas where pigs are routinely controlled with meat baits (www.birdata.com.au). However, we cannot discount effects to other 
Table 3. Change in density of taxa (birds $\mathrm{km}^{-2}$ ) between pre- and postbaiting surveys on Culgoa (the treatment site) and Kulki, North Kulki and Tambingey (pooled, control sites). Approach follows Westbrooke et al. (2003)

\begin{tabular}{|c|c|c|c|c|}
\hline Taxon & Trial & $\begin{array}{l}\text { Net } \\
\text { change by } \\
\text { treatment }\end{array}$ & Culgoa & $\begin{array}{l}\text { Kulki, } \\
\text { North Kulki, } \\
\text { Tambingey }\end{array}$ \\
\hline \multirow[t]{4}{*}{ Corvids } & May 2011 & +2.02 & +3.00 & +0.98 \\
\hline & Nov 2011 & -0.54 & -1.60 & -1.05 \\
\hline & May 2012 & +0.91 & +0.31 & -0.61 \\
\hline & Mean difference & +0.80 & +0.57 & -0.23 \\
\hline \multirow[t]{4}{*}{ Australian Magpie } & May 2011 & -0.72 & -0.77 & -0.05 \\
\hline & Nov 2011 & -0.27 & -0.12 & +0.16 \\
\hline & May 2012 & +0.27 & -0.07 & -0.34 \\
\hline & Mean difference & -0.24 & -0.32 & -0.08 \\
\hline \multirow[t]{4}{*}{ Wedge-tailed Eagle } & May 2011 & +0.14 & +0.07 & -0.07 \\
\hline & Nov 2011 & +0.11 & +0.13 & +0.02 \\
\hline & May 2012 & +0.03 & +0.01 & -0.03 \\
\hline & Mean difference & +0.09 & +0.07 & -0.03 \\
\hline \multirow[t]{4}{*}{ Falconidae $^{1}$} & May 2011 & -0.34 & +0.04 & +0.38 \\
\hline & Nov 2011 & +0.32 & +0.33 & +0.01 \\
\hline & May 2012 & +1.32 & +0.10 & -1.22 \\
\hline & Mean difference & +0.43 & +0.16 & -0.28 \\
\hline \multirow[t]{4}{*}{ Australian Kestrel } & May 2011 & +0.08 & +0.01 & -0.06 \\
\hline & Nov 2011 & +0.14 & +0.15 & +0.01 \\
\hline & May 2012 & +0.21 & +0.10 & -0.11 \\
\hline & Mean difference & +0.15 & +0.09 & -0.06 \\
\hline \multirow[t]{4}{*}{ Pied Butcherbird } & May 2011 & -0.55 & -0.50 & +0.05 \\
\hline & Nov 2011 & +0.31 & +0.18 & -0.13 \\
\hline & May 2012 & +0.39 & +0.01 & -0.39 \\
\hline & Mean difference & +0.05 & -0.11 & -0.16 \\
\hline \multirow[t]{4}{*}{ Grey Butcherbird } & May 2011 & -0.20 & -0.10 & +0.10 \\
\hline & Nov 2011 & -0.50 & -0.31 & +0.19 \\
\hline & May 2012 & -0.03 & -0.10 & -0.07 \\
\hline & Mean difference & -0.24 & -0.17 & +0.07 \\
\hline \multirow[t]{4}{*}{ All birds (pooled) } & May 2011 & -1.51 & -0.73 & +0.77 \\
\hline & Nov 2011 & +0.07 & -1.34 & -1.41 \\
\hline & May 2012 & +2.80 & +0.30 & -2.51 \\
\hline & Mean difference & +0.46 & -0.59 & -1.05 \\
\hline
\end{tabular}

${ }^{1}$ Falconidae consists of two species recorded, the Brown Falcon and the Black Falcon.

species, nor discount any historical or long-term changes in species composition or abundance from meat baiting. Nevertheless, Culgoa is well known for its avian diversity ( $>180$ species), and there are no anecdotal evidence or data to suggest any species loss or decline that has coincided with baiting practices (Andy Coward, Culgoa Floodplain National Park pers. comm. 2014). Varanids are one group of nontarget species that may be susceptible, and are known bait consumers (Woodford et al. 2012), but were not surveyed during this study. Future monitoring of varanids through a baiting campaign is warranted to determine any population-level impacts. Nevertheless, we conclude that the lack of effect on nontarget bird populations supports the continued use of 1080 meat baits to con- trol feral pigs in western Queensland and similar environs.

\section{Management implications}

While the results of this study indicate little risk to nontarget bird populations, it remains important to minimise nontarget exposure to meat baits to keep the risk low and to maximise uptake by pigs. There are options for reducing the nontarget uptake of meat baits, including distributing baits in the late afternoon/evening, dyeing baits green, covering or burying baits or using feeding deterrents, only placing toxic bait where feral pigs are feeding, or using pig-specific feeders (McIlroy 1983; McIlroy et al. 1993; Hone 2002; Elsworth et al. 2004; Bengsen et al. 2011; Mitchell 2011). However, many of these techniques would preclude the aerial application of

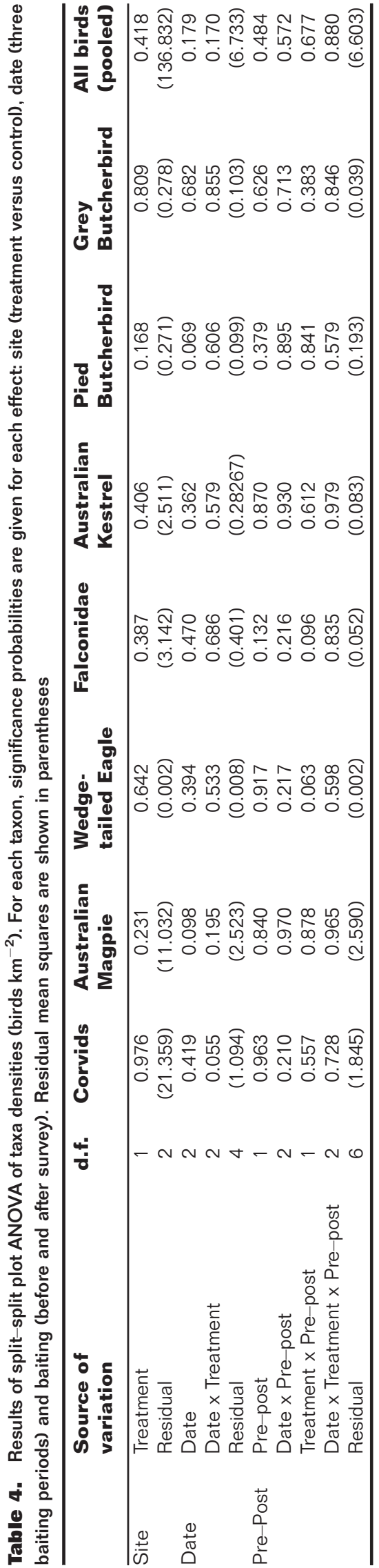


baits, or restrict current strategies, ultimately reducing the cost-effectiveness relative to other ground-based control techniques. Varanid uptake of meat baits may be easily reduced through distributing baits during the cooler months when ectotherms, like the lace monitor, are less active (Jessop et al. 2013). The benefits of such strategies need to be balanced against possibly compromising the proposed outcomes of the baiting campaign (e.g. to reduce environmental impacts).

Aerial baiting offers significant logistical and economic advantages to ground baiting for broadscale control, but such a strategy can increase availability to nontarget species, particularly when pigs have a restricted or localised distribution (Mitchell 2011). Ground baiting can be highly effective (e.g. Twigg et al. 2005) especially with prior free-feeding and targeting preferred foraging habitats (Mitchell 2008; Bengsen et al. 2014). While there are a variety of alternative bait types available for ground baiting (Mitchell 2011), options for aerial deployment are limited. The one alternative 1080 bait currently available for broadscale pig control (Pigout $^{\mathrm{TM}}$, Animal Control Technologies Australia) offers shelf stability and ease of handling and is reportedly target specific in most parts of Australia (Cowled et al. 2006) except areas of the Queensland wet tropics (Bengsen et al. 2011). Alternative toxins and delivery systems are currently being developed for feral pigs (Cowled et al. 2008), but will still provide potential risks to nontarget consumers given the large doses required to kill pigs. While it remains important to continue to improve baiting practices to minimise the likelihood of nontarget deaths, the results from this study are reassuring, with negligible nontarget avian impacts in semi-arid environs.

\section{Acknowledgements}

The project was approved under the DAFF animal ethics committee CA 2011/10/549. Sincere thanks to Amanda Millar, Michael Brennan, Catherine Hughes and Peter Elsworth for field assistance. Amanda Miller collected the bait-uptake data during the November 2011 trial. Thanks to Andy Coward (Culgoa Floodplain National
Park), Bruce Wilson (North Kulki and Tambingey) and Kelvin and Tammy White (Kulki) for access to their properties and assistance throughout the trial. Thanks to Kerry Bell for statistical advice and Jim Mitchell, Bob Parker, Joe Scanlan and two anonymous referees for comments that improved the manuscript.

\section{References}

APVMA (2008) Sodium Fluoroacetate Final Review Report and Regulatory Decision the Reconsideration of Registrations of Products Containing Sodium Fluoroacetate and Approval of Their Associated Labels. Australian Pesticides and Veterinary Medicine Authority, Kingston.

Bengsen A. J., Leung L. K. P., Lapidge S. J. and Gordon I. J. (2011) Target-specificity of feral pig baits under different conditions in a tropical rainforest. Wildlife Research 38, 370379.

Bengsen A. J., Gentle M. N., Mitchell J. L., Pearson H. E. and Saunders G. R. (2014) Impacts and management of wild pigs, Sus scrofa, in Australia. Mammal Review 44, 135-147.

Bibby C. J., Burgess N. D. and Hill D. A. (1992) Bird Census Techniques. Academic Press, New York.

Buckland S. T. (2006) Point-transect surveys for songbirds: Robust methodologies. Auk 123 345-357.

Buckland S. T., Anderson D. R., Burnham K. P. and Laake J. L. (1993) Distance Sampling: Estimating Abundance of Biological Populations. Chapman and Hall, London.

Chan K. (2001) Partial migration in Australian landbirds: A review. Emu 101, 281-292.

Cowled B. D., Lapidge S. J., Smith M. and Staples L. (2006) Attractiveness of a novel omnivore bait, PIGOUT ${ }^{\circledR}$, to feral pigs (Sus scrofa) and assessment of risks of bait uptake by non-target species. Wildlife Research 33 , 651-660.

Cowled B. D., Elsworth P. and Lapidge S. J. (2008) Additional toxins for feral pig (Sus scrofa) control: Identifying and testing Achilles' heels. Wildlife Research 35, 651-662.

DEEDI (2009) Toxin 1080 - A Guide to Safe and Responsible use of Sodium Fluoroacetate in Queensland. Department of Employment, Economic Development and Innovation, Brisbane.

DEWHA (2010) Survey Guidelines for Australia's Threatened Birds: Guidelines for Detecting Birds Listed as Threatened Under the EPBC Act. Department of the Environment, Water, Heritage and the Arts, Canberra.

Eason C., Miller A., Ogilvie S. and Fairweather A. (2011) An updated review of the toxicology and ecotoxicology of sodium fluoroacetate (1080) in relation to its use as a pest control tool in New Zealand. New Zealand Journal of Ecology 35, 1-20.

Elsworth P. G., Mitchell J. L. and Parker R. W. (2004) Evaluation of attractants and toxins for improved target specificity in the control of feral pigs. Report to the National Feral Ani- mal Control Program. Queensland Department of Natural Resources and Mines.

Fleming P. J. S., Choquenot D. and Mason R. J. (2000) Aerial baiting of feral pigs (Sus scrofa) for the control of exotic disease in the semiarid rangelands of New South Wales. Wildlife Research 27, 531-537.

Gentle M. (2005) Factors affecting the efficiency of fox (Nulpes vulpes) baiting practices on the central tablelands of New South Wales. Unpublished PhD thesis, School of Biological Sciences, University of Sydney, Sydney.

Gentle M. and Pople A. (2013) Effectiveness of commercial harvesting in controlling feral pig populations. Wildlife Research 40, 459-469.

Gentle M., Speed J., Mitchell J. and Dorney B. (2008) Effective 1080 baiting for feral pigs. Final Report to the National Feral Animal Control Program, Bureau of Rural Sciences. Department of Primary Industries and Fisheries, Toowoomba.

Glen A. S., Gentle M. N. and Dickman C. R. (2007) Non-target impacts of poison baiting for predator control in Australia. Mammal Review 37, 191-205.

Hone J. (2002) Feral pigs in Namadgi National Park, Australia: Dynamics, impacts and management. Biological Conservation 105 231-242.

Hone J. and Pedersen H. (1980) Changes in a feral pig population after poisoning. In: Proceedings of the Ninth Vertebrate Pest Conference (ed J. P. Clark) pp. 176-182. University of California, Davis.

Jessop T. S., Kearney M. R., Moore J. L., Lockwood T. and Johnston M. (2013) Evaluating and predicting risk to a large reptile (Varanus varius) from feral cat baiting protocols. Biological Invasions 15, 1653-1663.

Mcllroy J. C. (1983) The sensitivity of Australian animals to 1080 poison. V.* The sensitivity of feral pigs, Sus scrofa, to 1080 and its implications for poisoning campaigns. Australian Wildlife Research 10, 139-148.

Mcllroy J. C. (1984) The sensitivity of Australian animals to 1080 poison VII.* Native and introduced birds. Australian Wildlife Research 11, 373-385.

Mcllroy J. C., Gifford E. A. and Forrester R. I. (1993) Seasonal Patterns in Bait Consumption by Feral Pigs (Sus scrofa) in the Hill Country of South-eastern Australia. Wildlife Research 20,637-651.

Millar A. (2012) Assessing non-target interaction with sodium fluoroacetate (1080) feral pig (Sus scrofa) bait using camera traps. Unpublished Honours thesis, School of Agriculture and Food Sciences, University of Queensland.

Milson J. (1997) Plant Identification in the Arid Zone. Department of Primary Industries, Queensland, Brisbane.

Mitchell J. (1998) The effectiveness of aerial baiting for control of feral pigs (Sus scrofa) in North Queensland. Wildlife Research 25 , 297-303.

Mitchell J. (2008) Feral Pig Control: A Practical Guide to Pig Control in Queensland. Queensland Department of Primary Industries \& Fisheries, Brisbane.

Mitchell J. (2011) Feral Pig Control. NQ Dry Tropics, Townsville.

Sinclair R. and Bird P. (1984) The reaction of Sminthopsis crassicaudata to meat baits con- 


\section{RESEARTH REPORT}

taining 1080: Implications for assessing risk to non-target species. Australian Wildlife Research 11, 501-507.

Thomas L., Buckland S. T., Rexstad E. A. et al. (2010) Distance software: Design and analysis of distance sampling surveys for estimating population size. Journal of Applied Ecology 47, 5-14.

Twigg L. E. and Kay B. J. (1994) Changes in the relative abundance of raptors and house mice in western New South Wales. Corella 18, 83-86.
Twigg L. E., Lowe T., Martin G. and Everett M. (2005) Feral pigs in north-western Australia: Basic biology, bait consumption, and the efficacy of 1080 baits. Wildlife Research 32 , 281-296.

Van Dyck S. and Strahan R. (2008) The Mammals of Australia, 3rd edn. New Holland Publishers, Sydney.

Westbrooke I. M., Etheridge N. D. and Powles land R. G. (2003) Comparing methods for assessing mortality impacts of an aeria
1080 pest control operation on tomtits (Petroica macrocephala toitoi) in Tongariro Forest. New Zealand Journal of Ecology 27, 115-123.

Woodford L. P., Robley A., Maloney P. and Reside J. (2012) The impact of 1080 bait removal by lace monitors (Varanus varius) on a red fox (Vulpes vulpes) control programme. Ecological Management \& Restoration 13 306-308. 